\title{
Effectiveness of whole body vibratory stimulation for fall prevention in super-aged women: a preliminary randomized trial
}

\author{
Byeong-Soo Kim ${ }^{a}$, Kang-Uk Lim ${ }^{a}$, In-Seon Baek ${ }^{a}$, Min-Kyoung Kim ${ }^{a}$, Hye-Min Kang ${ }^{b}$, \\ Gi-Jeong Nam ${ }^{b}$, Myung-Mo Lee ${ }^{a}$ \\ ${ }^{a}$ Department of Physical Therapy, College of Health and Medical Science, Daejeon University, Daejeon, Republic of Korea \\ ${ }^{b}$ Department of Social Welfare, College of Social Sciences, Daejeon University, Daejeon, Republic of Korea
}

Objective: The aim of this study is to investigate the effects of whole body vibratory stimulation on muscle strength, balance, and fall efficacy among super-aged women.

Design: Randomized controlled trial.

Methods: Twenty-eight super-aged women over 80 years of age were assigned to either the experimental group $(\mathrm{n}=14)$ and control group $(\mathrm{n}=14)$. The experimental group received an exercise program that used the whole body vibratory stimulation with a frequency of $30 \mathrm{~Hz}$ and amplitude of $3 \mathrm{~mm}$, and the control group received an exercise program without vibratory stimulation. Intervention was provided for 4 weeks, 3 sessions per week, and 30 minutes per session. In order to measure lower extremity muscle strength the 30-second chair stand test (CST) was used. The Berg Balance Scale (BBS) was used to measure dynamic balance. Static balance was measured by tracking the path length, velocity, and area of the center of pressure (CoP). The Falls Efficacy Scale (FES) was used to measure the subjects' fear of falling.

Results: Both the experimental and control group demonstrated statistically significant increase in muscle strength, dynamic balance, and fall efficacy $(p<0.05)$. Only the experimental group showed significant improvements in static balance before and after the intervention $(p<0.05)$. The experimental group showed significantly greater improvements in CST, BBS, and CoP (path length, velocity) than control group $(p<0.05)$.

Conclusions: Whole body vibratory stimulation exercise is shown to be a safe and appropriate physical therapy intervention method to enhance muscle strength, balance, and fall efficacy of super-aged women.

Key Words: Accident prevention, Aged, Postural balance, Vibration, Women

\section{Introduction}

According to Statistics Korea, the number of people over 65 years of age was 7.38 million, constituting $14.3 \%$ of the total population in 2018 [1], and it is prospected that 1 out of 5 people will be over the age of 65 years, entering a super-aged society in 2025 . The increase in the elderly population is not only a social problem, but also becomes a health issue. One of the health issues that may arise due to decrease in physical function in the elderly population is falls. According to Statistics Korea [2], 21.0\% of the population over 65 years of age has experienced falls in 2016, and the hospital admission rate due to falls was $72.4 \%$, where $47.4 \%$ have experienced residual effects due to falls. This illustrates the point that fall incidents are increasing along with the increase in the elderly population. Falls are a serious events that jeopardizes the health of the elderly population, and it is declared as the cause of increase in morbid-

Received: 15 January, 2019 Revised: 21 February, 2019 Accepted: 22 February, 2019

Corresponding author: Myung-Mo Lee (ORCID https://orcid.org/0000-0002-2192-1701)

Department of Physical Therapy, College of Health and Medical Science, Daejeon University, 62 Daehak-ro, Dong-gu, Daejeon 34520 , Republic of Korea Tel: 82-42-280-4295 Fax: 82-42-280-2295 E-mail: mmlee@dju.kr

(c) This is an Open-Access article distributed under the terms of the Creative Commons Attribution Non-Commercial License (http://creativecommons.org/licenses/ by-nc/4.0) which permits unrestricted non-commercial use, distribution, and reproduction in any medium, provided the original work is properly cited.

Copyright (๑) 2019 Korean Academy of Physical Therapy Rehabilitation Science 
ity death rates $[3,4]$.

Physical disability acquired through falls is difficult to recover, and it is considered as a serious health issue because of the high risk for complications when compared with the younger population $[5,6]$. In addition, normal activities are limited by not only physical impairments, but also by fear of falling, and furthermore, there is a decrease in physical function, resulting in a high risk for falls [7]. Muscle mass decreases due to aging and subsequently leads to decreased muscle strength, endurance, muscle atrophy, and contraction [8]. Additionally, degeneration of somatic senses, visual, vestibular, and central nervous impairments, and other deteriorations are factors that increase the risk of falls by causing problems in balance and gait abilities $[9,10]$.

Gradual resistance exercises may improve the functional status of an elderly person apart from improving the heart function, and muscle strengthening exercises may prevent muscle deterioration [11]. Therefore, various exercise programs have been developed and implemented to decrease the incidence of falls among the elderly population. Some of the most emphasized targets within the programs for fall prevention are increasing lower extremity muscle strength, endurance, and balance [12]. Improvements in balance, muscle strength, and gait are reported to have significant correlations with the quality of life of the elderly population [13].

Recently, the whole body vibrator has been introduced as a method of enhancing muscle function by applying new stimuli to the muscles through synthetic and quantitative control of gravity without putting too much pressure on the body $[14,15]$. The whole body vibrator provides various frequencies of vibration to stimulate the somatic senses of the participant, and is effective in increasing muscle strength and bone density. There are previous studies that report significant increases in muscle contraction and strength when the whole body vibrator is used in young adults and the elderly [16-18]. Other literature reports effectiveness in postural stability and decreased risk of falls in the elderly $[19,20]$. Specifically, Cheung et al. [21] have reported improvements in directional control and motor velocity in women over 70 years of age, suggesting that the whole body vibration is an applicable intervention method for the super-aged population.

Prior Korean studies that have used the whole body vibrator reports various participant groups, such as athletes [22,23], stroke patients [24], obese women [25], children with cerebral palsy [26], and people with spinal cord injury $[27,28]$, but there are no studies on the effects of the whole body vibrator for the super-aged population over 80 years of age. Therefore, this study aims to investigate the effects of muscle strength, balance, and fall efficacy of super-aged women in their 80 s who used the whole body vibrator and clinical implications, and recommend it as a fall prevention intervention method by increasing balance and muscle strength.

\section{Methods}

\section{Participants}

Seventy-six women who were over 80 years of age who lived in Jung Hwa nursing facility located in Iksan were recruited for this study. The inclusion criteria were super-aged elderly over 80 years of age, able to perform independent activities of daily living, able to walk 15 minutes or more without any assistance, able to perform a semi-squat for $10 \mathrm{sec}-$ onds, and scored 24 or higher on the Korean version of the Mini-Mental State Examination. The exclusion criteria were women who were diagnosed with nephrotic, hepatic, or cognitive problems, used a pacemaker, any osteopathic issues that may affect the study outcomes, intends to drop out from the study, and participated less than $80 \%$ of the intervention. All of the participants were given full explanation of the study purpose, content, procedures, participant rights, and safety issues. The participants agreed and signed the written consent before participating in the study. This study was approved by the Ethical Committee of Daejeon University (IRB No. 1040647-201804-HR-017-01). Written informed consent.

\section{Procedures}

This study was a before-after controlled trial and used G-Power ver. 3.1 (Heinrich-Heine-University Düsseldorf, Düsseldorf, Germany) to determine the number of participants. Based on the main effect outcomes from the preceding research [29] the effect size was set to $\mathrm{d}=0.938$, significance level $\alpha=0.05$, and power of the test $(1-\beta)=0.8$, and at least 13 participants were required for each group. Considering the dropout rate of $15 \%$, a total of 30 participants were selected for the preliminary evaluation with 15 participants for each group. The participants were given 2 papers that had numbers 1 or 2 written on it and were assigned to one of the two groups according to the number they had chosen. The participants were assigned to either the experimental group $(n=15)$ or the control group $(n=15)$. The experimental group received the whole body vibration ex- 
ercise program along with conventional physical therapy, and the control group received only conventional physical therapy. After the 4-week intervention program, post-intervention evaluation was conducted, and pre- and post-intervention values were statistically analyzed (Figure 1).

\section{Intervention}

The whole body vibration system (SW-VH11; SONIX, Wonju, Korea) was used for the whole body vibration exercise program. The exercise program modified the intervention methods of the preceding study by Bautmans et al. [30]. The exercise program was composed of (1) (ant-post/ right-left) weight bearing, (2) tandem standing, (3) calf raise, (4) tiptop raise, (5) semi-squat $\left(10-15^{\circ}\right)$, and (6) one-legged stand, considering the physical condition of the super-aged elderly. Five minutes before and after the exercise were comprised of stretching for the purpose of warming-up and cooling down, and the whole body vibration exercise was performed for 20 minutes. In order to control the exercise intensity, the first week consisted of performing exercises (1), (2), (3), and (4) for 20 seconds each, totaling up to $80 \mathrm{sec}-$ onds, which was considered as 1 set. A resting period of 90 seconds was given between each set. The second week consisted of performing exercises (1), (2), (3), (4), and (5) for 20 seconds each, totaling up to 100 seconds, which was considered as 1 set. A resting period of 60 seconds was given between each set. The third week consisted of performing exercises (1), (2), (3), (4), (5), and (6) for 20 seconds each, totaling up to 120 seconds, which was considered as 1 set. A resting period of 60 seconds was given between each set.

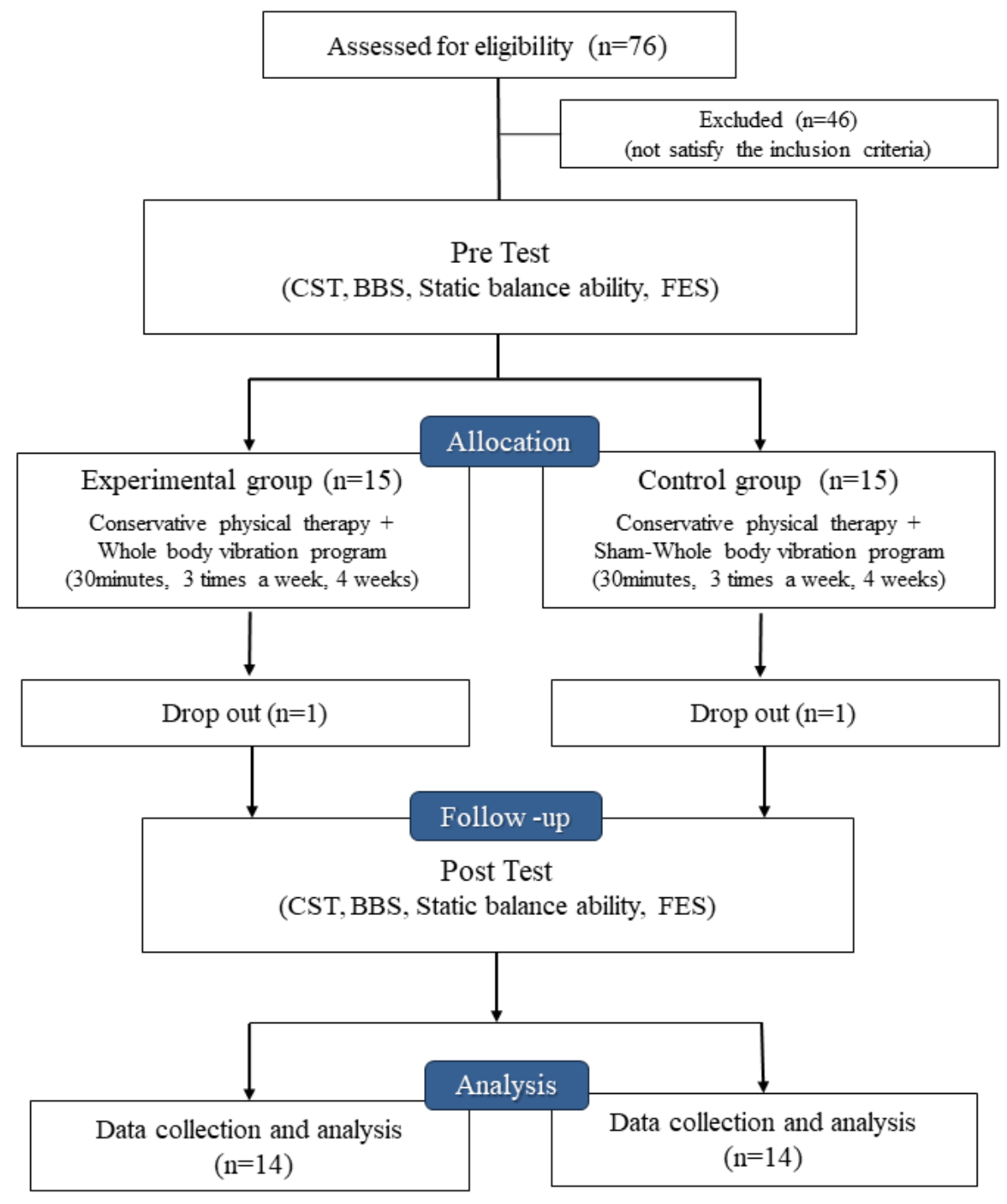

Figure 1. Flow chart of this study. CST: chair stand test, BBS: Berg Balance Scale, FES: Falls Efficacy Scale. 
The fourth week consisted of the same intervention as the third week with a resting period of 20 seconds between each set. The experimental group performed the exercises standing on top of the whole body vibrator, and the control group performed exercises without any vibration stimuli. After all the intervention sessions were completed, participants who volunteered were provided with the same exercise program with the whole body vibration. The vibration frequency was set to $30 \mathrm{~Hz}$ and the amplitude was set to $3 \mathrm{~mm}$ as according to Di Giminiani et al. [31] The whole body vibration exercise program was administered for 30 minutes per session 3 times a week for 4 weeks. In order to prepare for any potential adverse events from the vibration, such as shaking of the head or dizziness, four research assistants were present.

\section{Measurement tools}

In order to measure lower extremity muscle strength, the 30-second chair stand test (CST) was conducted [32]. It was measured by counting the number of sit to stands performed within 30 seconds with both arms across the chest. The average was obtained after three measurements.

To assess dynamic balance, the Berg Balance Scale (BBS) was utilized. The BBS is a balance test that can predict the risk of falls of the elderly population in the community and consists of 14 components, each scored from 0 to 4 , with a total score of 56 . The average value was obtained after three measurements. For static balance ability, the movement distance, speed, and moving area of the center of pressure (CoP) were assessed by using the Wii balance board while maintaining static posture with the subject standing comfortably for 30 seconds. The collected data was analyzed using the Balancia software. The fear of falling during performance of activities of daily living was evaluated by using the Falls Efficacy Scale (FES) [33]. It assesses the subjects' fear of falling during the performance of 10 different types of actions required for the performance of daily living activities, each scored from 1 to 10 . The point system ranges from the minimum of 10 points to a maximum of 100 points, where the lower score, the greater the fear of falling.

\section{Analysis}

The collected data was analyzed using PASW Statistics ver. 18.0 (IBM Co., Armonk, NY, USA). The general characteristics of the participants are provided through descriptive statistics and standard deviation values, and the Shapiro-Wilk test was conducted to test for normality. The general characteristics and the homogeneity test of pre-
Table 1. General characteristics of participants

$(\mathrm{N}=28)$

\begin{tabular}{lcrc}
\hline \multicolumn{1}{c}{ Variable } & $\begin{array}{c}\text { Experimental } \\
\text { group }(\mathrm{n}=14)\end{array}$ & $\begin{array}{c}\text { Control group } \\
(\mathrm{n}=14)\end{array}$ & $\mathrm{t}(p)$ \\
\hline Age $(\mathrm{y})$ & $83.14(3.92)$ & $84.00(3.80)$ & $-0.587(0.562)$ \\
Height $(\mathrm{cm})$ & $146.39(5.97)$ & $148.64(5.16)$ & $-1.067(0.296)$ \\
Weight $(\mathrm{kg})$ & $55.82(11.29)$ & $58.50(9.40)$ & $-0.682(0.501)$ \\
$\begin{array}{c}\text { Body mass } \\
\text { index }\left(\mathrm{kg} / \mathrm{m}^{2}\right)\end{array}$ & $25.96(4.48)$ & $26.49(3.98)$ & $-0.332(0.742)$ \\
\hline
\end{tabular}

Values are presented as mean (SD).

measured values were analyzed for differences within groups using the independent t-test. Comparisons of effects before and after the interventions within groups were analyzed using the paired t-test. Statistical significance of this study was set to $\alpha=0.05$.

\section{Results}

Within the experimental and control groups, 1 participant in each group withdrew from the study due to not fulfilling the participation rate criteria. Ultimately, the data of 14 participants in the experimental group and 14 participants in the control group were collected for analysis. The general characteristics of participants are described in Table 1, and homogeneity between the groups was determined.

The results of the 30-second CST that was used to determine the changes in lower extremity muscle strength showed significant improvements $(p<0.05)$ in the before and after intervention measurements for both groups, and the experimental group showed a greater significant increase $(p<0.05)$ compared with the control group.

The BBS results showed significant improvements in the before and after intervention measurements for both groups $(p<0.05)$, and the experimental group showed a significant difference $(p<0.05)$ (Table 2$)$.

The path length, velocity, and area $95 \%$ were measured for static balance. The results showed that only the experimental group demonstrated a significant decrease $(p<0.05)$ in path length and CoP velocity before and after the interventions, and the experimental group showed a significant difference compared with the control group $(p<0.05)$ (Table 3).

The FES was used to measure fall efficacy of the participants, and both groups showed significant improvements for before and after intervention measurements. However, the before and after intervention FES values between the two groups were not statistically significant (Table 3 ). 
Table 2. Comparison of lower extremity muscle strength and dynamic balance ability between groups $(\mathrm{N}=28)$

\begin{tabular}{lcrc}
\hline Variable & Experimental group $(\mathrm{n}=14)$ & Control group $(\mathrm{n}=14)$ & $\mathrm{t}(p)$ \\
\hline CST (score) & & & $-0.530(0.601)$ \\
Pre & $6.920(1.660)$ & $8.300(2.100)$ & $2.925(0.007)$ \\
Post & $9.700(1.460)$ & $-1.360(1.200)$ & $-1.051(0.303)$ \\
Pre-post & $-2.790(1.290)$ & $-4.241(0.001)$ & $3.671(0.001)$ \\
$\mathrm{t}(p)$ & $-8.053(<0.001)$ & & \\
BBS (scores) & & $41.500(5.320)$ & \\
Pre & $39.500(4.740)$ & $44.360(5.930)$ & $2.860(3.010)$ \\
Post & $47.290(2.490)$ & $-3.553(0.004)$ & \\
Pre-post & $7.780(4.020)$ & $-7.242(<0.001)$ &
\end{tabular}

Values are presented as mean (SD).

CST: 30-second chair stand test, BBS: Berg Balance Scale.

Table 3. Comparison of static balance ability and fall efficacy between groups

\begin{tabular}{|c|c|c|c|}
\hline Variable & Experimental group $(n=14)$ & Control group $(\mathrm{n}=14)$ & $\mathrm{t}(p)$ \\
\hline \multicolumn{4}{|c|}{ CoP path length $(\mathrm{cm})$} \\
\hline Pre & $87.270(8.110)$ & $87.180(7.150)$ & $0.030(0.976)$ \\
\hline Post & $81.580(9.030)$ & $87.450(11.705)$ & \\
\hline Pre-post & $5.690(6.690)$ & $-0.260(7.830)$ & $2.162(0.040)$ \\
\hline $\mathrm{t}(p)$ & $3.180(0.007)$ & $-0.126(0.902)$ & \\
\hline \multicolumn{4}{|c|}{ CoP velocity $(\mathrm{cm} / \mathrm{s})$} \\
\hline Pre & $2.910(0.270)$ & $2.910(0.240)$ & $0.044(0.965)$ \\
\hline Post & $2.720(0.300)$ & $2.910(0.390)$ & \\
\hline Pre-post & $0.180(0.220)$ & $-0.010(0.260)$ & $2.130(0.043)$ \\
\hline $\mathrm{t}(p)$ & $3.193(0.007)$ & $-0.123(0.904)$ & \\
\hline \multicolumn{4}{|l|}{ CoP area $95 \%$} \\
\hline Pre & $5.420(1.820)$ & $4.940(1.950)$ & $0.664(0.512)$ \\
\hline Post & $6.480(2.150)$ & $5.520(1.910)$ & \\
\hline Pre-post & $-1.070(2.310)$ & $-0.570(2.130)$ & $-0.584(0.564)$ \\
\hline $\mathrm{t}(p)$ & $-1.724(0.108)$ & $-1.012(0.330)$ & \\
\hline \multicolumn{4}{|l|}{ FES (scores) } \\
\hline Pre & $74.290(17.830)$ & $74.500(14.550)$ & $-0.035(0.972)$ \\
\hline Post & $86.140(16.990)$ & $83.360(15.590)$ & \\
\hline Pre-post & $-11.860(10.305)$ & $-8.860(8.500)$ & $0.838(0.410)$ \\
\hline $\mathrm{t}(p)$ & $-4.286(0.001)$ & $-3.898(0.002)$ & \\
\hline
\end{tabular}

Values are presented as mean (SD).

CoP: center of pressure, FES: Falls Efficacy Scale.

\section{Discussion}

Whole body vibration is a new form of exercise that stimulates the muscles with the mechanism of tonic vibration reflex to resist vibration stimuli while maintaining a position. Different muscles may be targeted depending on various positions made on top of the whole body vibrator, and it is an exercise applicable by only maintaining the position without any excessive pressure or resistance. Specifically, this meth- od of training may be provided to the elderly as a safe and easy exercise without any risk of potential danger of involving the cardiovascular system or producing muscle overuse [32]. Over the years, whole body vibration was introduced as a training method for various geriatric diseases and the elderly. This study investigated the effects of whole body vibration on lower extremity muscle strength, balance, and fall efficacy of super-aged elderly women over 80 years of age. The results confirmed that this training method is effective 
in enhancing balance.

Functional muscle strength of the lower extremities was measured using the 30-second CST. Compared with the results from before the intervention, the experimental group showed an increase of $40.2 \%$ (Cohen's $d=1.770$ ) and $18.6 \%$ (Cohen's $\mathrm{d}=0.639$ ) for the control group. Both groups showed a statistically significant increase $(p<0.05)$, but the experimental group had a significantly greater increase compared with the control group $(p<0.05)$. Whole body vibration exercise consists of two factors of vibration stimuli and unloaded exercise (regarding the posture made on top of whole body vibrator). Although just by maintaining positions offered in the study's exercise program without vibration stimuli may be seen as effective in increasing muscle strength of the elderly, the increases in muscle strength after application of the whole body vibration is certainly affected by the vibration stimuli. As existing studies suggested, whole body vibration stimuli promotes reflexive contraction of the muscle by stimulating the muscle spindle, and the stimulation may have promoted muscle activation more effectively than without any stimulation. When the results of this study are simply compared with resistance exercises, it conforms to existing studies that suggest vibratory stimulation exercises are major factors in increasing muscle strength [33,34]. Among the studies, Machado et al. [35] reported that whole body vibration exercises conducted on 13 women who had mean age of 79 years may prevent decreases in muscle strength and mobility caused by aging.

Prior to the study, the intensity of the exercise program for the super-aged elderly over the age of 80 years was an immense consideration. Many participants reported that the vibration stimuli that they have never experienced were difficult to adjust. Regardless of the difficulties, there was only 1 participant that dropped out from each group. Unlike the study by Bautmans et al. [30] which included 1 set of exercise session that lasted 8 minutes, the exercise program of this study consisted of a warm-up and cool down period along with a gradual increase in intensity, which was considered to be appropriate for super-aged elderly. In addition, the interest in health and following a regular lifestyle of the participants may have had positive effects.

Along with lower extremity muscle strength, both groups showed a significant increase in dynamic balance before and after the intervention. The BBS results showed 19.7\% (Cohen's d=2.050) improvement in the experimental group and $6.9 \%$ (Cohen's $\mathrm{d}=0.510$ ) for the control group illustrating that the two groups resulted in significant difference in before and after the intervention measurements. Additionally, the experimental group showed a greater significant difference than the control group.

The application of the whole body vibration exercise also showed a significant difference between groups in static balance ability. The measurement results of the path length and velocity of the CoP showed a significant difference only in the experimental group (path length $=6.5 \%$, Cohen's $d=0.660$; velocity $=6.5 \%$, Cohen's $\mathrm{d}=0.670$ ), and there was a greater significant contribution to postural stability than the control group. The BBS is a gold standard clinical tool that allows the anticipation of fall risks and assesses dynamic balance. This study supports the study by Pollock et al. [36] that BBS scores have increased from 37.93 before exercise to 48.50 after 8 weeks of exercise in the those over 80 years of age. In addition, it also conforms with the study of Legters et al. [37] where whole body vibration exercise was performed with squatting for 12 weeks among 21 participants who were over 60 years of age, and the BBS score had significantly increased from 48.50 to 53.10 . Additionally, whole body vibration exercises activate the muscle spindle by stimulating sensory receptors in the joints and muscles and ultimately activating proprioceptive function [38]. This induces reflexive contraction of the lower extremity and trunk muscles that contribute to postural stability and sensory and motor nervous systems are strongly stimulated to increase postural control $[17,39]$.

Increases in muscle strength and postural control after whole body vibration are also related to decreased frequency of falls. Bruyere et al. [20] reported that the risk of falls was significantly decreased after whole body vibration exercise in elderly population aged 63 to 98 years. Bogaerts et al. [39] reported that risk of fall was significantly decreased as well as increasing postural control after whole body vibration exercise in 94 elderly participants. Verschueren et al. [17] demonstrated that fall risk factors have significantly decreased in 25 participants after performing whole body vibration exercise for 24 weeks. In the study by Pollock et al. [36], 77 participants aged 80 years and who had a fall experience were assigned to whole body vibration exercise group $(n=38)$ or the control group ( $n=39)$, and both groups had significant increases in fall efficacy after 3 sessions of intervention per week for 8 weeks. This study used FES to determine whether the effects of whole body vibration exercise would relieve the fear of falling. The study resulted in improving fall efficacy by increasing $15.9 \%$ (Cohen's $\mathrm{d}=0.560$ ) from 74.29 to 86.14 in the experimental group and $11.9 \%$ 
(Cohen's d $=0.580$ ) from 74.50 to 83.36 in the control group, but there was no significant difference in the changes between groups before and after the intervention. This may be due to the ceiling effects of the measurement results of the elderly participants who were greatly determined to independently perform their daily living activities within the nursing facility.

Factors that decide the effects of whole body exercise are frequency, amplitude, and velocity, with the most important factor being frequency. Many studies of the effects of various frequencies of whole body vibration show different results. This study utilized the frequency of $30 \mathrm{~Hz}$ and the amplitude of $3 \mathrm{~mm}$ as suggested by Rittweger [40] and Di Giminiani et al. [31]. These studies reported that the frequency of $20-50 \mathrm{~Hz}$ is enough to increase muscle strength, and $30 \mathrm{~Hz}$ is effective and safe for muscle activation.

These results may suggest that whole body vibration exercise is an effective program for super-aged elderly participants over the age of 80 years when appropriately constructed and frequency and amplitude are considered. However this study had a few limitations. First, participants without any particular issues with physical function were selected; thereby it is difficult to generalize the result to all super-aged elders over 80 years of age. The second limitation is that individual lifestyle habits, environmental factors, and nutritional status were difficult to control due to various dwelling habits in a nursing facility. Thirdly, the durability of the intervention effects cannot be confirmed. Further studies need to minimize these limitations along with other problems that may rise and investigate the long-term effects of whole body vibration exercise in super-aged elders with geriatric conditions by designing an appropriate exercise program.

In conclusion, this study aimed to investigate the effects of applying a whole body vibrator on muscle strength, balance, and fall efficacy of super-aged women over 80 years of age. The results showed that the whole body vibrator is a safe and applicable exercise method to increase muscle strength and balance. Future studies are warranted to confirm the effects of the whole body vibrator on other impairments from a wider range of subjects, and the results may need to be reviewed for clinical usability.

\section{Acknowledgements}

This work was supported by the Korea Foundation for the Advancement of Science \& Creativity (KOFAC), and fund- ed by the Korean Government (MOE) (No. 20180217).

\section{Conflict of Interest}

The authors declared no potential conflicts of interest with respect to the authorship and/or publication of this article.

\section{References}

1. Korea national statistical office [Internet]. Daejeon: Statistics Korea. [cited 2018 Dec 16]. Available from: http://kostat.go.kr/ portal/korea/kor_nw/1/6/1/index.board?bmode $=$ read \& $\mathrm{aSeq}=370779$.

2. Korea national statistical office [Internet]. Daejeon: Statistics Korea. [cited 2018 Dec 16]. Available from: http://kosis.kr/ statHtml/statHtml.do?orgId=101\&tblId=DT_1BPA001\&conn_ path $=\mathrm{I} 2$.

3. Miller CA. The connection between drugs and falls in elders. Geriatr Nurs 2002;23:109-10.

4. Dehail P, Cressot V, Delleci C, Nozères A. [Gait and balance disorders. Falls in the elderly]. Rev Prat 2011;61:575-80. French.

5. Rubenstein LZ, Josephson KR. Falls and their prevention in elderly people: what does the evidence show? Med Clin North Am 2006;90:807-24.

6. Hwang SJ. Risk of falls in community-dwelling older adults aged 65 or over with type 2 diabetes mellitus: a systematic review. Phys Ther Rehabil Sci 2018;7:139-45.

7. Denkinger MD, Igl W, Lukas A, Bader A, Bailer S, Franke S, et al. Relationship between fear of falling and outcomes of an inpatient geriatric rehabilitation population--fear of the fear of falling. J Am Geriatr Soc 2010;58:664-73.

8. Spirduso WW, Francis K, Eakin T, Stanford C. Quantification of manual force control and tremor. J Mot Behav 2005;37:197-210.

9. Hess JA, Woollacott M. Effect of high-intensity strength-training on functional measures of balance ability in balance-impaired older adults. J Manipulative Physiol Ther 2005;28:58290.

10. Kannus $P$, Sievänen $H$, Palvanen $M$, Järvinen $T$, Parkkari J. Prevention of falls and consequent injuries in elderly people. Lancet 2005;366:1885-93.

11. Taylor AW, Johnson MJ. Physiology of exercise and healthy aging. Leeds: Human Kinetics; 2007.

12. Runge M, Rehfeld G, Resnicek E. Balance training and exercise in geriatric patients. J Musculoskelet Neuronal Interact 2000;1: 61-5.

13. Kim MC, Ahn CS, Kim YS. The effect of exercise program for falls prevention on balance and quality of life in the elderly women. J Korean Soc Phys Med 2010;5:245-54.

14. Rittweger J, Just K, Kautzsch K, Reeg P, Felsenberg D. Treatment of chronic lower back pain with lumbar extension and whole-body vibration exercise: a randomized controlled trial. Spine (Phila Pa 1976) 2002;27:1829-34.

15. Park JH, Choi WJ, Lee SW. Effects of immediate unilateral whole body vibration on muscle performance and balance in young adults. Phys Ther Rehabil Sci 2013;2:115-8. 
16. Roelants M, Delecluse C, Verschueren SM. Whole-body-vibration training increases knee-extension strength and speed of movement in older women. J Am Geriatr Soc 2004;52:901-8.

17. Verschueren SM, Roelants M, Delecluse C, Swinnen S, Vanderschueren D, Boonen S. Effect of 6-month whole body vibration training on hip density, muscle strength, and postural control in postmenopausal women: a randomized controlled pilot study. J Bone Miner Res 2004;19:352-9.

18. Roelants M, Verschueren SM, Delecluse C, Levin O, Stijnen V. Whole-body-vibration-induced increase in leg muscle activity during different squat exercises. J Strength Cond Res 2006;20: 124-9.

19. Bosco C, Colli R, Introini E, Cardinale M, Tsarpela O, Madella A, et al. Adaptive responses of human skeletal muscle to vibration exposure. Clin Physiol 1999;19:183-7.

20. Bruyere O, Wuidart MA, Di Palma E, Gourlay M, Ethgen O, Richy F, et al. Controlled whole body vibration to decrease fall risk and improve health-related quality of life of nursing home residents. Arch Phys Med Rehabil 2005;86:303-7.

21. Cheung WH, Mok HW, Qin L, Sze PC, Lee KM, Leung KS. High-frequency whole-body vibration improves balancing ability in elderly women. Arch Phys Med Rehabil 2007;88:852-7.

22. Oh JH, Kang SR, Min JY, Kwon TK. The Effect in the muscle function following 8-week dead-lift training with whole-body vibration in rehabilitation for sports players. Korean J Sport Biomech 2015;25:344-52.

23. Lee JH. Whole-body vibration and training. J Korea Content Assoc 2015;13:14-7.

24. In TS, Song CH. The effects of whole body vibration on knee extensor strength, and balance and walking ability with chronic stroke. J Korean Soc Phys Med 2010;5:675-83.

25. Moon HW, Sunoo S. The effect of whole body vibration training and diet cure on body composion, physical fitnes s and blood lipid of elderly obese women. The Journal of Physical Education 2004;32:199-208.

26. Jung JM, Choi SJ, Shin WS. The effect of whole body vibration training on balance and trunk strength ability in cerebral palsy patients. Nat Sci 2014;25:1-15.

27. Ahn MC, Song CH. Immediate effects of local vibration on ankle plantarflexion spasticity and clonus of both the gastrocnemius and soleus in patients with spinal cord injury. J Korean Soc Phys Med 2016;11:1-11.

28. Asakawa Y, Lee MM, Song CH. The effect of whole body vibration training on postural sway in patients with spinal cord in- jury: a pilot study. Phys Ther Rehabil Sci 2013;2:70-4.

29. Kim YM, Park JH. The effect of whole-body vibration exercise on balance, muscle strength and falls efficacy in the elderly. J Korean Soc Phys Med 2017;12:61-71.

30. Bautmans I, Van Hees E, Lemper JC, Mets T. The feasibility of Whole Body Vibration in institutionalised elderly persons and its influence on muscle performance, balance and mobility: a randomised controlled trial [ISRCTN62535013]. BMC Geriatr 2005; 5:17.

31. Di Giminiani R, Masedu F, Tihanyi J, Scrimaglio R, Valenti M. The interaction between body position and vibration frequency on acute response to whole body vibration. J Electromyogr Kinesiol 2013;23:245-51.

32. Byun JJ, Lee KJ. The effect of Whole Body Vibration on physical functions in elderly persons : a quantitative review. J Coach Dev 2009;11:211-20.

33. Cardinale M, Bosco C. The use of vibration as an exercise intervention. Exerc Sport Sci Rev 2003;31:3-7.

34. Delecluse C, Roelants M, Verschueren S. Strength increase after whole-body vibration compared with resistance training. Med Sci Sports Exerc 2003;35:1033-41.

35. Machado A, García-López D, González-Gallego J, Garatachea $\mathrm{N}$. Whole-body vibration training increases muscle strength and mass in older women: a randomized-controlled trial. Scand J Med Sci Sports 2010;20:200-7.

36. Pollock RD, Martin FC, Newham DJ. Whole-body vibration in addition to strength and balance exercise for falls-related functional mobility of frail older adults: a single-blind randomized controlled trial. Clin Rehabil 2012;26:915-23.

37. Legters K, Verbus NB, Kitchen S, Tomecsko J, Urban N. Fear of falling, balance confidence and health-related quality of life in individuals with postpolio syndrome. Physiother Theory Pract 2006;22:127-35.

38. Burke D, Schiller HH. Discharge pattern of single motor units in the tonic vibration reflex of human triceps surae. J Neurol Neurosurg Psychiatry 1976;39:729-41.

39. Bogaerts A, Verschueren S, Delecluse C, Claessens AL, Boonen S. Effects of whole body vibration training on postural control in older individuals: a 1 year randomized controlled trial. Gait Posture 2007;26:309-16.

40. Rittweger J. Vibration as an exercise modality: how it may work, and what its potential might be. Eur J Appl Physiol 2010; 108:877-904. 